Please refer to the published version when citing:

Janta, H., Cohen, S.A. \& Williams, A.M. (2015). Rethinking visiting friends and relatives mobilities. Population, Space and Place, DOI: 10.1002/psp.1914.

\title{
RETHINKING VISITING FRIENDS AND RELATIVES \\ MOBILITIES
}

\section{Hania Janta, Scott A Cohen and Allan M Williams, Faculty of Business, Economics and Law, University of Surrey}

\begin{abstract}
The increasing number of people leading more mobile lives, with spatially dispersed families, raises questions over how they maintain their family life and friendships, and how this is shaped and shapes different forms of migration, and different patterns of Visiting Friends and Relatives (VFR). This paper develops an explanatory framework for conceptualizing and analyzing VFR mobilities, seeking to draw together threads from migration, mobilities and tourism studies. In unpacking the notion of VFR, this paper understands VFR mobilities as being constituted of diverse practices, and discusses five of the most important of these: social relationships, the provision of care, affirmations of identities and roots, maintenance of territorial rights, and leisure tourism. While these five types of practices are considered sequentially in this paper, they are in practice often blurred and overlapping. The interweaving of these practices changes over time, as does the meaning and content of individual practices, reflecting changes in the duration of migration, life cycle stage, individual goals and values, and the broader sets of relationships with and social obligations to different kin and friends.
\end{abstract}

Keywords: VFR, migration, mobilities, tourism, kinship, friendship 


\section{INTRODUCTION}

Visiting friends and relatives (VFR) constitutes a major component of mobility and temporary migrations, with substantial economic, cultural and networking implications, but it has been relatively neglected by researchers. Concern has frequently focused only on estimating the scale of VFR travel (e.g Moscardo et al., 2000; Seaton and Palmer, 1997; Backer, 2012), rather than unpacking the complex social relations, obligations, instrumentality and meanings of home(s), away and in-between that are embedded in VFR. VFR travel is an example of Sayer's (1992) 'chaotic conceptualization', being longer on empirical observation than theoretical understanding of a diverse set of constitutive population flows. It is enmeshed in the web of relationships around diasporas, transnationalism, inter-generational transitions, and the reaffirmation and re-creation of (hybrid) identities. To some extent, the neglect of VFR reflects how it fell into the interstices at the meeting point of migration, mobilities and tourism. However, recently there have been increasing, and more searching, analyses of VFR by migration(King, 2011b, 2011c), mobility(Larsen et al., 2007) and tourism researchers (Williams and Hall, 2002). One reason for the relatively poor conceptualization of VFR mobility is that it has often been dis-embedded from considerations of the nature of family and friendship, and the obligations that are incumbent within these. While there is some overlap between these, as argued below, family and friendship obligations need to be considered separately.

VFR mobility first emerged as a substantial social phenomenon in early modern industrialism when erosion of centralized authority in kinship structures undermined the prevailing norm that mobility should involve all kin (Litwak and Szelenyi, 1969). These were subsequently reinforced by two broad cultural developments, individualization and secularization, as well as the growth of the welfare state, labour market shifts and massive expansions in educational provision and opportunities in late modernization (Liefbroer and Murden, 2006). Sociologists have long been concerned with the implications of these macro social and cultural changes for the systems of obligations at the heart of kinship norms. In their landmark study, Rossi and Rossi (1990) demonstrated the persistence of 
relatively strong family norms relating to hierarchical obligations to provide material and emotional support to family members, including regular or periodic visits. Widely held societal beliefs, or norms, about family obligations serve as parameters which shape how individuals understand and negotiate their responsibilities (Finch, 1989). Moreover, the expectations and the needs of kin change over the life cycle, tending to be most intense for dependent children, and for frail elderly relatives.

While friendship also involves obligations, these are voluntary practices which lack the institutional framework of the family (Hardimon, 1994), are less formal and more easily dissolved. Instead, 'mutual liking, shared experiences, care, and trust are the core elements of friendship' (Annis, 1987: 350). However, as 'friendship develops, an intricate web of reciprocal and mutual dispositions, beliefs, understandings, feelings, etc., develops' (p. 354). Similarly to kinship, there is a hierarchy of different levels of friendship, with differential expectations, and these are commonly expressed in terms such as casual versus close versus best friends. Close friends - unlike casual friends - are defined by willingness to give support and participate in self disclosure (Jourard, 1971). Particular events are often critical in shifts between different levels of friendship, between becoming or being excluded from friendship (Baxter and Bullis, 1986: 470). These are turning points, 'occasions of heightened intensity in which the pressures of dialectical interplay change the relationship in some way' (Baxter and Erbert, 1999: 551). Distance resulting from migration often constitutes such a critical turning point (Johnson et al., 2003: 224).

A key issue for this paper is whether geographical proximity is a prerequisite for maintaining close relationships with kin and friends. Extensive debate in the mid twentieth century, concluded that geographical proximity is not a necessary condition for either close kinship (Litwak, 1960) or friendship relationships (Litwak and Szelenyi, 1969), but also acknowledged that the frequency and nature of the constitutive interactions are influenced by proximity (Silverstein and Litwak, 1993). A key issue is the selectiveness with which relationships are maintained at a distance, after a migration-induced turning point. 
Migration turning points are likely to pose greater challenges for (some levels of) friendship than for kinship relationships. Rose and Serafica (1986) found that frequency of contact was less critical, and deeply embedded affection was more important in maintaining close friendships, while distance tended to end causal friendships because of the weakening of maintenance behaviours (Canary and Stafford, 1994). Some maintenance behaviours, such as undertaking joint activities, are constrained by distance, but Johnson (2001) found no significant differences between proximate and distant friends in their evaluation of the openness and assurances which characterized their friendships.

In part, Johnson's findings reflect the importance of technological shifts. More recently, cost reductions realized via low cost airlines have provided opportunities for enhanced mobilities - perhaps as circulating migrants, or through more frequent visits by distanciated friends and family (Dobruszkes, 2009). They also create new geographies of mobilities as low cost airlines connect previously disconnected peripheral regions (Graham and Shaw, 2008) and define new migrations at both the intra- and extra-European scales (Burrell, 2011). Radical innovations in information and communications technologies (e.g. via Skype) have also revolutionized the costs and immediacy of electronic communication, and their role in sustaining friendships. While there is a debate as to whether purely internetmediated friendships are possible (Briggle, 2008), more germane here is Wellman et al's (2001) observation that most relationships formed on the internet spill over into co-present interchanges, creating communities characterized by enfolded online and offline interactions (Rheingold, 2000). In other words, the internet can generate VFR mobilities, as well as sustaining existing relationships.

This issue of Population, Space and Place focuses on questions surrounding the relationship between VFR mobilities, migration and tourism. The articles are outcomes of a think tank held at University of Surrey (UK) in June 2013 (Palovic et al., 2014). This overview paper brings together the diverse practices that constitute VFR mobilities, and examines their multiple purposes and meanings, in order to reconceptualize VFR mobilities. We discuss five of the most important of these: social relationships, the 
provision of care, affirmations of identities and roots, maintenance of territorial rights, and leisure tourism. The meaning, and the maintenance of social relationships has already been partially addressed in the introduction. One of the most important of these social relationships is constructed around obligations to provide care, which includes a variety of related practices (Finch, 1989), both material and emotional. VFR mobilities are also important in reaffirming, and reshaping identities and 'return visits', whether as part of the myth of return, as preparations of return, or the second and subsequent generations' search for roots (Christou and King, 2010); all represent performances of identities, as do the lessresearched visits to the migrants. These practices are related to Urry's (2002) typology of co-present interactions. We consider those interactions in our analysis of VFR practices. Additionally, VFR mobilities can involve practices designed to assert various forms of territorial rights, relating to taxation, voting, and other citizenship entitlements, as well as place-bound consumption practices. Finally, VFR leisure tourism is a form of hybrid travel (King, 1996) where leisure practices are mixed with other practices (Moscardo et al., 2000).

While these five types of practices are considered separately in this paper, they are often blurred and overlapping. The experience of each practice evolves over time, reflecting changes in the life cycle stage, individual goals and values and duration of migration. The directions of VFR mobilities also change over time, with 'stayers' and 'leavers' traveling in both directions, challenging the traditional dichotomy between mobile migrants and static non-migrants.

\section{SOCIAL RELATIONSHIPS: EXPECTATIONS, NORMS AND TRUST}

Much of the literature on VFR, mostly in tourism studies, fails to differentiate even the most basic division between visiting friends and visiting relations (Moscardo et al., 2000). Yet migration as a turning point (Baxter and Erbert, 1999) has very different meanings and implications, involving different practices, depending on the specific type of kinship and friendship relationships, as indicated earlier. 
Bonding and parenting efforts that migrating parents perform in sustaining family ties through transnational communication and visits between migrant parents and their leftbehind children can be a source of emotional strain involving pain, regret and disappointment (Ryan et al., 2009; McGhee et al., 2013; Hoang and Yeoh, 2012). As physical separation continues, communication via phone calls can have a different meaning for children and parents. For the growing-up children, it may become a burden rather than a blessing - as children feel more comfortable with less direct communication such as texts. Several studies (Wellman and Hampton, 2001; Hoang and Yeoh, 2012) have shown that communication technologies help in maintaining contact and exchanging support; members of transnational families can stay up to date with one another's day-to-day affairs. Despite that, they do not necessarily create a shared social field for migrant parents - older children may see parents' efforts to show love and care via the phone as a form of surveillance, discipline and control (Hoang and Yeoh, 2012).

Maintaining romance at a distance poses a different set of challenges. When it comes to love and intimacy - hope, anticipation and expectations are relevant notions in performing to-and-from movement. Urry (2002) emphasizes that 'face to face' co-presence allows observing another person's body language, hearing what they say and developing extended relations of trust - elements of particular importance in romantic relationships. Walsh's (2009) study of Britons in Dubai, McGhee et al.,'s (2013) study of Poles in the UK and Klekowski von Koppenfels et al., 's (this issue) study of highly-skilled Americans and French in London reveal that new types of communication are not always sufficient to sustain close relationships over distances, where these involve important physical elements.

Visiting friends has received less attention than visiting kin. The implications of migration as a turning point tend to be seen as different for friendship compared to kinship because of voluntariness, lack of institutional ties and the potential availability of alternative friends (Blieszner and Adams, 1992; Johnston et al., 2003). Johnson et al., (2003)'s study examined whether friendships, defined as casual, close, or best, differ when experiencing turning points, amongst which migration can be considered one of the most significant. Although friendships can be fostered at-a-distance, on the Internet, not requiring any co- 
presence (Briggle, 2008), VFR mediates the outcome of this turning point. Visits from friends offer scope for renewing trust and social bonding, including narrating and creating shared memories, even if their objectives range from the common pursuit of shared pleasures, to celebrating significant life course events, to furthering career and economic interests. These visits to friends constitute a driving force of modern tourism, as well as significant outcomes of migration - as is also the case with visits to family. They take on increasingly diverse spatial forms, with visits to third spaces, complementing those between the homes/home areas of the participants. Conradson and Latham (2005) emphasize the centrality of friendships networks to patterns of mobility in their study of New Zealanders in London. However, not surprisingly, friendship groups often 'move on' and are no longer willing to invest the required effort - as demonstrated in Mueller's study of German professionals in England (this issue) or Hong Kong migrants from mainland China (Hung et al., 2013).

The timing of VFR visits, or what Urry (2002) terms 'facing the moment' is of particular significance - visiting home is often driven by performing rituals, yearly events sometimes of religious character. Sharing a lamb at Orthodox Easter, saying thanks as a family on Thanksgiving Day, or lighting firecrackers together on Chinese New Year are all important yearly events that cement family ties. Celebrations of important life course events of our significant others; marriages, births, graduations and funerals are also relevant here. The obligatory nature of those events means that, when there is little or no advance notice, as with death or illness, timing as well as financial means to buy last minute tickets is critical (Larsen et al., 2007). Sustaining the life of family and friendship networks by copresence at special moments is at the core of VFR mobility. Although there are expectations that the migrant rather than the non-migrant does the visit (Baldassar, 2001; Mason, 2004), VFR mobilities take place in both directions, and the life stage of those involved, as well as the rhythm of the year, are also significant. For example, studentrelated VFR mobility is structured by the academic year (Bischoff and Koenig-Lewis, 2007). 
In many ways, maintaining social life at-a-distance is not cost free, in either material or psychological terms (Larsen et al., 2007). Visiting and hosting is sometimes enjoyable but can be tedious, tiring and expensive. These costs are unevenly distributed because ' $[t]$ he lure of free accommodation means that people living in interesting places are especially likely to receive guests' (Larsen et al., 2007, p.253). Those guests may sometimes have unrealistic expectations of their family and kin, confusing the sense of welcome, of hospitality and its extent, and of how they should be hosted, entertained and fed. Visits from children can be valued (King et al., 2011c) but they can also be problematic, with some visitors overstaying and disrupting daily routines (Williams et al., 2000). Such visits may contradict rather than meet the expectations of kinship and friendship. Larsen et al., (2007) warns that in this case VFR travel may be damaging to social relations - they argue that it takes place because the location and free accommodation are prized over the relationship. In contrast to hosts' experiences, VFR tourists in a foreign place might cognitively and emotionally move from strangeness to familiarity ('feeling at home') as

they are 'hosted' and taken care of by their significant others (Uriely, 2010). However, the expectations surrounding the visit, especially in respect of the self-disclosure that is central to close friendship, can also be disappointed, which has particular significance for friendship, given its more voluntary dimension and the existence of different categories of friends (Jourard, 1971). Visits may confirm close friendships, or lead to realizations that these are now more akin to casual friendships.

\section{VFR AND CARE PRACTICES}

Migration has significant implications for providing support and care for it represents not only brain drain but also 'care drain' (Isaksen et al., 2008); while most marked for family, this is not insignificant for some friendships. Family - let alone friendship - obligations to provide care are not dictated by norms and expectations, but are negotiated commitments (Finch, 1989), whereby family members evaluate the appropriateness of the obligations and their costs. Not surprisingly, in their benchmark study of the family, Rossi and Rossi (1990) found that commitments to familial care obligations were contingent on which family 
members were involved, and the type of care involved. Even amongst children and parents, who recognized the strongest family obligations, many did not believe they necessarily had to support adult children or older parents. In part this reflects the balance between individualist and collectivist cultures. The picture is complicated because while older households in more developed countries have tended to favour maintaining separate households and 'intimacy at a distance' (Finch, 1989: 94-5), this poses different challenges in later life, especially during the transition from the active elderly to the frail elderly stage. In short, different kin assume changing importance at different stages of the life cycle so that families should be understood as 'fluid and constantly being reconstituted and negotiated, adapting across spaces and through time' (Kofman, 2004: 249).

There also tends to be a division of caregiving amongst kin. Whereas caregiving was traditionally viewed as being largely the preserve of kin who lived in close proximity (Lin and Rogerson, 1995), it is increasingly recognized that '(...) contributions to caregiving by distant carers were part of a negotiated set of decisions between kin, the transnational migrant being incorporated in family help patterns - called on if and when other kin were unavailable or to provide support for other kin' (Baldock, 2000: 320). However, VFR care provision is part of the process of adaptation, negotiating and the division of labour in care provision, informed by various considerations, including the strength of the feelings of obligation.

Although caregiving is fluid and negotiable, it is strongly gendered. There is some evidence that gender differences between sons and daughters in providing care decline with distance (Cicirelli, 1995), but Stoller et al., (1992) contend that gender norms often eclipse proximity/distance effects. Mothers especially prefer to receive personal care from daughters rather than sons, irrespective of proximity. And, even if distance does have an overall neutralizing effect on gender norms, there are persistent gender differences in the types of care provided at a distance: men were more likely to provide support for business affairs, maintenance and repairs, while women tend to offer emotional and health support 
(Baldock, 2000). There is little evidence of how these gendered differences translate into VFR-related care, but there are clearly significant implications.

Care can be delivered by a variety of means, including electronically at a distance, and visits of varying duration. Almost inevitably these are blended, and the blend changes over time in response to the changing circumstances and needs of both the givers and receivers of care. This leads us to consider how proximity/distance mediate the delivery of the main types of support and care identified by Finch (1989). The first of these is, sharing accommodation which, by definition, requires immediate proximity, so that VFR mobility is not an issue for those immediately concerned, although it may be for other family members or friends. It is relatively common among young adult friends. Amongst family in more developed countries, the preference for intimacy at a distance, combined with changes in mobility and resources, has meant a decline in multi-generational households not containing dependent children. However, this tendency may be reversed by economic crises, especially amongst adult children who are constrained to rely on their parents for accommodation. The other key point in the life cycle is the frail elderly stage, where individuals are faced with choices/constraints of relying on institutional care, or sharing with children or, sometimes, friends.

The next two types, personal care and nursing, and child care and practical support, are instrumental forms of support where frequent and/or immediate care is required, as is copresence. Not surprisingly, the provision of instrumental care, whether assisting elderly relatives with intimate tasks, or looking after children regularly or occasionally, declines with distance (De Jong, et al., 1998; Joseph and Hallman, 1998). Irrespective of causality in this association (Mulder and Kalmijn, 2006), proximate children tend to provide more instrumental support than those at a distance. The latter may help in other ways, however, including financial assistance to buy-in non familial care, providing emotional support, or visiting occasionally to provide covering support or relief for their more proximate siblings. However, the "tyranny of distance" is a significant barrier to more equitable sharing of 
caregiving (Joseph and Hallman, 1998). Even where distant relatives visit to provide direct instrumental support, their responsibilities are 'compartmentalised' (Baldock, 2000: 321) to fit in with the spatialities and temporalities of their 'other' lives.

Fourthly, the provision of economic support at a distance is a long established practice. In a monetary economy, money is the most important, and sometimes the only form of economic support provided (Litwak and Szelenyi, 1969: 468). This is recognized in the labour migration literature as remittance behaviour. Remittances can be provided for various purposes, including provision for the planned return of the migrant, as well as economic support for the family left behind (King et al., 2011c). It can be provided at a distance, although some migrants - either lacking trust in financial institutions, or due to the importance of co-presence in rituals of gift giving - may prefer to make such transfers during return visits, as VFR mobility practices. Where economic and regulatory constraints necessitate prolonged absence from family, economic support becomes a substitute for, or form of commodification of, love (Parreñas, 2005), in place of providing face-to-face support. Remittance practices vary across the life cycle, not only of the recipients but also their children, as well as the marital status of the latter (King et al., 2011c). In addition to labour migrant remittances, inter-generational resource transfers are relatively common, both in the form of gifts and financial support, such as parents helping adult children to buy a house, or children supplementing parents' pensions (Hagestad, 2000). While gift giving within families is informed by both affection and moral obligation, that to friends is guided more by affection (Komter and Vollerbergh 1997). Whilst such transfers can be made at a distance, the rituals of gift giving often involve face-to-face transfers, perhaps as part of family events, such as landmark birthdays, wedding anniversaries, or the death of one of the donating parents. Furthermore, goods brought from 'home' on a return visit are culturally and identity laden. For example, the home-made food gifted to Greek students in the UK by family and friends provides a sense of stability and continuity of the idealised Greek home (Petridou 2001). As Burrell (2008: 370) suggests: 'Travelling suitcases full of 
gifts and apparently mundane products are just as important as emails, telephone calls and Skype for keeping the migrants feeling connected'.

Fifthly, the provision of moral and emotional support is an essential obligation of kinship, while - as noted earlier - mutuality of sharing, trust and caring are defining features of close friendship. Annis (1987: 352) argues that: 'It isn't merely that it is nice for friends to help, to provide psychological support, but that we expect friends to act this way, are surprised if they don't, and frequently feel betrayed and not just harmed if they intentionally let us down'. The critical question, for friends or family, is the extent to which affective communication can be provided by distanciated communication (Octavia et al., 2007). De Jong Gierveld and Fokkema (1998) consider the exchange of emotional support is not significantly influenced by distance, but this discounts the physical contacts, and the reading of body language, which require co-presence. In one of the few studies of the impact of separation (including migration) on friendship practices, Octavia et al., (2007) report that sharing problems and feelings (78\%) was considered the greatest loss, followed by physical contacts $(50 \%)$ such as hugs or holding hands. Body language and facial expressions tell friends if you are having a problem, even when unable to start explaining this, and you want those friends to realize this and ask what is wrong (Octavia et al., 2007).

\section{MIGRATION, MOBILITIES, ROOTS AND IDENTITIES}

While VFR may not necessarily be tied to any specific territory because of increased globalization and mobility - roots, ethnic, diasporic, genealogical, ancestral or heritage visits are place-specific. Variously defined, all these terms refer to ancestors' homeland visits, motivated by self-discovery, the search for one's roots, belonging and homecoming (King, 1994). Conceptualized by Urry (2002) as 'facing the place' (presence in places), such visits entail sensing a place directly, such as walking within a neighbourhood or visiting specific buildings. 'Facing the place' VFR practices, to seek out, and affirm roots, vary across generations. For first generation migrants, they can be triggered by particular 
events such as a parent dying, middle-aged crisis, retirement, or children finishing school (Ruting, 2012). For migrants' children and subsequent generations, childhood narratives of bonds of culture, religion and national identity (Coles and Timothy, 2004) can trigger a search for reaffirmation and performance of one's own heritage.

Basu $(2004,2007)$ uses the concept of 'roots tourism' to describe North American travellers who visit their ancestors' homeland in Scotland, driven by the search for belonging and homecoming. Their journey is seen as pilgrimage and a 'life-changing experience' (Basu, 2004: 151). Wessendorf (2007), building on this concept, develops 'roots migration' to term the migration of the second generation to their parents' homeland. Here, in contrast to Basu's tourists, those migrants' connections to the homeland are based on everyday translocal practices which took place during their childhood and adolescence. However, the meaning of 'roots' and 'rootedness' is not static - idyllic memories of holiday visits are sometimes contrasted with disappointing 'return'. A disjuncture between migrants' and non-migrants' journeys is termed the 'ossification effect' by Levitt (2009). Returned migrants can be deeply disappointed when faced by changes (Hoffman, 1991; Karanfil, 2009), that stand in sharp contrast to images of the 'old country' conveyed by their parents (Jain, 2013). Hence, second generation migrants' 'roots' can be 'lost' when this other place is transformed from imagined to real (Wessendorf, 2007; 2010; Jain, 2013; King et al., 2011a, 2011b).

This does not mean that other homecoming migrants, whether first generation migrants or mobile workers, are free from experiences of loss and strangeness: they can experience lack of orientation, unfamiliarity with culturally-infused 'current slang', and a general feeling that 'home' is no longer as imagined (Uriely, 2010). Arguably, technological advances in communication and transport potentially have reduced the likelihood of abrupt discords between image and experience, with return visits constantly underlining the rapidity of social and linguistic changes. Contrary to those experiences, Teerling (2011) argues that new migrant cultures are created that cannot be reduced to, or simply understood in terms 
of, their association with either their 'host' or 'home' society. Her study of British-born Cypriots returning to their ancestral homeland showed that new 'third-cultural spaces of belonging' are established. These are formed around social relations that draw upon various sources, from being from the same life-cycle cohort to common interests. Similarly, 'cosmopolitan' second and third-generation Armenians in the US introduce a new set of ideas and practices embedded in cosmopolitan projects, such as engaging in global issues and internationalized social movements, after their return (Dariev, 2011). This demonstrates that those returning may introduce change and have a potentially significant impact on their ancestral society.

'Facing the place', or place-specific visits, are especially vital here - homecoming involves seeing landmarks and places. Looking for and visiting the houses, farms, worship places and graves of ancestors is also part of engaging in self-discovery (Basu, 2007: 28): '[a]ncestors' graves and houses (or their remnants) became powerful material objects that elicited deep feelings of historicity and identity'. In Iorio and Corsale's (2013) study, Transylvanian Saxons encountered a sense of alienation or exclusion, rather than belonging: their travel back to the homeland revealed a landscape they did not recognize anymore, a 'landscape of rupture'. Visiting individual graves, or concentrations camps such as Auschwitz, in different ways contain an emotional and private journey into troubled aspects of an ancestral past, and can be traumatic events.

The availability of historical archives online, probably reinforces rather than substitutes for such corporeal mobilities. Where earlier social networks have long withered, visits to some form of 'homeland' may still take place. Moreover, searching for roots, initially online, may lead eventually to a (re)discovery of long lost family ties, and the creation of new VFR networks. 


\section{MAINTENANCE OF TERRITORIAL RIGHTS AND PREFERENTIAL CONSUMPTION}

A number of other themes surrounding VFR movements remain unpacked. Embroiled in VFR mobilities are practices designed to assert various forms of territorial rights and residential attachment, as well as the preferential consumption of local, culturally informed services and specialized goods, such as those that are medical, dental and beauty-related. The latter, especially, may often constitute secondary objectives to visiting significant others and in returning to homelands. While migration has implications at the state level for issues such as citizenships rights and how consumer expenditure is distributed (Williams and Hall, 2000b), few studies have examined the transnational movements that migrants undertake to maintain these rights in multiple countries, or to purchase goods and services in the country to which one temporarily returns.

International migration often results in transnationalism, wherein migrants are embedded in social processes linked to two or more national-states (Bailey, 2001). Transnationalism, or the maintenance of homes or citizenship in multiple countries, has implications for one's legal status, and may be subject to different (supra)national legislations (Benson and O'Reilly, 2009b). Even in Europe, where the EU has sought to create a free movement space, transnational living often forces decisions over where to claim residency, which can affect tax levels, benefits, insurance and how long one can or must spend in a country to qualify for those (ibid). Regulatory frameworks can engender border crossing: fostering trips between countries to meet those criteria, wherein such needs can be 'piggybacked' with VFR.

The examination of transnational issues such as differential citizenship statuses, including variable social rights and welfare benefits, are not new to migration studies (e.g. Ackers and Dwyer, 2004; Geddes, 2003), but have typically focused on inequalities therein and how migrants negotiate such issues. The 'social security strategies' of older migrants, for 
instance, have been researched, with Böcker (2008: 105) focusing on how Dutch retirement migrants to Spain and Turkey "gain or retain access to public, private and family resources in their 'home' and their 'host' state to meet their social security needs" (ibid: 108), such as pension entitlements and access to health care. These practices are shaped by the legal frameworks of the 'home' and the 'host' states, as well as supranational (e.g. EU) rules, and in some cases, bilateral agreements (ibid).

What have been largely overlooked are the diverse mobilities associated with maintaining such rights and entitlements, which can be bundled in with a range of other motivations, and often cloaked under the practice of VFR. Many of these mobilities can be conceived as maintenance behaviours, and be viewed as 'banal mobilities' that illustrate how the everyday is imbricated in travel (Binnie et al., 2007). Such banal mobilities can relate to the renewal of visas, passports, driver licenses and other documentation, and maintaining electoral and taxation entitlements or social rights that are linked to various forms of residence. Some of these movements constitute grey areas that have been difficult to research, such as claiming benefits from a home country while living abroad, or (ab)using taxation loopholes afforded through transnational living arrangements.

The consumption of culturally nuanced services on homeland trips, such as those that are medical, dental and beauty-related, as well as products not available in the destination, are other mobility objectives that become bundled with VFR. For instance, King and Lulle (this issue) find that such services tend only to be used in the migrants' natal homeland, as emphasized by one Latvian migrant: 'All these things I only do in Riga'. Motivations include, for example, non-availability of goods or services in either the new or old 'home', lower prices, or in the case of return trips, cultural affinity and trust with a familiar consumption context (Lee et al., 2010). Accessing amenities such as medical or dental services (ibid; Bergmark et al., 2010), hairdressing and other personal services is largely attributed to the relative trust attached to the providers, as well as cost considerations, eligibility where relevant, and possible lack of fluency in a host language. Some well- 
resourced Korean migrants in New Zealand, for instance, return to Korea for health care because of preference for care in their own language, but also due to lack of adaption to New Zealand's health care system, and particular cultural beliefs and expectations surrounding treatment (Lee et al., 2010). There are thus affective elements sought in medical treatment by migrants on return visits, who may seek above all a culturally familiar experience.

Sometimes such medical visits are not just linked to preference, but relate also to unsuccessful treatment or lack of access, as in the case of Bergmark et al.,'s (2010) study of Mexican immigrants in northern California who returned to their natal homes in central Mexico for health-related reasons, often combining that objective with a family visit. Despite there being considerable anecdotal evidence and a handful of studies evidencing that migrants tend to return to use such 'home' services (Lee et al., 2010; Osipovic 2013), these mobilities are largely unresearched in migration, tourism and mobilities studies. Bergmark et al.,'s (2010) work though is good example of complex migrant VFR mobilities that are less tied to privilege, as the availability of VFR travel, motivated in part by the consumption of goods and services far from 'home', depends on access to economic, socio-technical and cultural resources (Cresswell, 2010). Typically those who migrated voluntarily, rather than having been forced or coerced, have the power to engage in such practices. It can be speculated that gradually this strong need to consume homeland products and services will decline, although this needs to be empirically researched.

\section{ENFOLDMENT WITH LEISURE TOURISM}

VFR constitutes a driving force of modern tourism. As early as the 1990s, Jackson's seminal article on VFR tourism contended that migration contributes to 'unrestricted tourism flows' and these arguments have gained conviction over time. Studies of VFR tourism tend to view it as a category within purpose of visit, alongside pleasure, business and other, or as a type of accommodation (Backer, 2012; Griffin, 2013). The underlying 
aim of such a view is to assess the potential economic value of VFR travelers in context of the tourism industry. Invariably VFR tourists are perceived as minor contributors to tourism receipts (Shani, 2011), who are beyond the influence of tourism planners (Seaton and Palmer, 1997), despite contrariwise evidence of their potentially significant economic impact (Backer, 2012). This business-oriented view comes at the expense of a wider grasp of how VFR mobilities are embroiled with a range of other practices, with leisure tourism being just one of potentially many. Thus much of the existing research on VFR travel has tended to focus on the size and importance of the VFR market for destinations (e.g Moscardo et al., 2000; Seaton and Palmer, 1997; Backer, 2012), although there is growing interest in the social and community dimensions of VFR tourism (Griffin, 2012; Shani, 2011).

VFR combines the fulfilment of social obligations with opportunities for tourism activities, which are often subsidized through free accommodation; thus VFR can be amenable to constrained budgets, and especially important at times of economic recession. It is a hybrid form of mobility where the balance of pleasure, leisure and kinship and friendship obligations co-mingle, with one or the other at times constituting the primary purpose of the visit (Moscardo et al., 2000). Visits occur in various directions: migrants spend resources on temporary returns to their 'home' country, but they also become attractions in their own right, generating visits from other friends and relatives (Griffin, 2013; Williams and Hall, 2000a). Shorter term visits are essential to the lives of migrants, and their families and friends, as well as to the survival and shaping of diasporic cultures. At the same time, VFR tourism may inform future migration, through the creation of 'search spaces' as well as mobility competencies (Williams and Hall, 2002). This is particularly evident when friends or relatives become lifestyle migrants to places perceived as offering a 'better' way of life (Benson and O'Reilly, 2009a), wherein tourism visits may tip into voluntary migration, both for the initial migrants and for those visiting them subsequently.

Three main aspects of leisure tourism within contemporary VFR mobilities are noted here: social issues surrounding hosting, the meanings associated with visitors' experiences, and 
the phenomena of VFR in third places. First, tourism-related VFR mobility is mediated by family and/or friends as 'hosts'. However, if those being visited are short term migrants in the destination, those hosts can be 'guests' themselves, illustrating the fuzziness of the hostguest relationship (Cohen and Cohen, 2012; Humbracht, this issue). This is particularly evident in Bischoff and Koenig-Lewis's (2007) study of international university students in the UK whose family and friends travel to visit them, such as for graduation ceremonies. Overall, very little is known about the VFR trips to shorter term migrants, although this is an important component of tourism demand and of mobility in general.

Particularly in the case of longer-term migrants, there are often tensions over who should travel and who should host, the 'stayer' or the 'leaver', as this can be demanding in terms of time and material resources, and social and economic opportunity costs. While visitors might pay travel expenses, 'hosts' often bear the costs of hospitality. In the case of Williams et al.,'s (2000) study of retired migrants from the UK who settled in Mediterranean destinations, valued 'visits from a distance' sometimes became cases where guests overstayed and disrupted daily routines. While hosting friends and relatives when living in an attractive tourism destination may include a loss of privacy and heightened expenditure, it can engender a sense of pride in place, provide self-justification to be at leisure (Shani and Uriely, 2012), and generally improve quality of life.

The majority of studies of VFR tourism have focused on the experiences of returning visitors as opposed to hosts (Griffin, 2013). Those studies that have sought to unpack the social meanings of VFR experiences from the visitor perspective commonly highlight the perception that 'the old home ain't what it used to be' (Uriely, 2010). This theme of return visits as a source of dissatisfaction is also evident in studies on second generation migrants, whose idyllic memories of holiday visits are contrasted with disappointing 'return'. Returning migrants from Switzerland to Italy, from Germany to Greece and from the UK to Cyprus, amongst others, find challenges and reactions that differ from their happy childhood memories of holiday returns (Wessendorf, 2007; 2010; King et al., 2011a; 
2011b). Wagner's (this issue) microanalysis of Rabia's visit to Morocco demonstrates how she fails in her attempts to be characterized as a 'local' during a shopping trip. Despite her efforts to bargain for a 'local price', and the company of her relatives, she is left with a negative sense of being 'other' during her encounter with a vendor. However, VFR tourists in a foreign place might cognitively and emotionally move from strangeness to familiarity ('feeling at home') as they are 'hosted' and taken care of by their significant others (Uriely, 2010). Hence VFR tourism can be a convergence of both 'home' and 'away' for visitors, or a "complex phenomena in which elements of both "extraordinary" and "everydayness" coexist' in tourism practices (Shani, 2011:1).

Lastly, there are increasing instances of VFR in third places wherein neither family nor friends have hosting responsibilities. In some cultural and national contexts, a second home (e.g. a summer cottage) co-owned by family members, can constitute both a connection to family roots as well as a joint holiday space for family and friends (Hiltunen et al., 2013) As VFR mobilities take on increasingly diverse spatial forms, visits to third places for holidays to meet family and/or friends can complement or supplant those between the homes/home areas of the participants. Their objectives range from the common pursuit of shared pleasures and activities, to the celebration of significant life course events. Complex family relations and the existence of spatially dispersed multiple homes of family members drive family reunions in new destinations other than the natal home. Cheap and accessible transport makes these reunion visits possible: another deficit in VFR research is consequently how such visits to third places have been shaped by contemporary transport changes, and how if at all they influence future migration.

\section{CONCLUSIONS: RETHINKING VISITING FRIENDS AND RELATIVES MOBILITIES}

This article outlines a framework for conceptualizing and analyzing some of the nuances of VFR mobilities, drawing together threads from migration, mobilities and tourism studies. In an attempt to unpack the notion of VFR, this paper understands VFR mobilities as being 
constituted of diverse practices, and discussed five of the most important of these: social relationships, the provision of care, affirmations of identities and roots, maintenance of territorial rights, and leisure tourism.

The implications of sustaining kinship and friendship ties are mostly considered separately in sociology, and the migration turning point is likely to pose different challenges for these. While VFR mobility tends to be seen positively in terms of celebration of milestone life course events and rituals structured around these, such visits are not unproblematic. There are often tensions over who should travel and who should host, as this can be demanding in terms of time and material resources, and emotions. Moreover, as contended by Larsen et $a l$. , (2007), hosting and visiting can also challenge social relations when there are tensions between different practices - say meeting the expectations of close relationships versus leisure pursuits.

One of the most important of these social relationships is constructed around obligations to provide care, which includes a variety of related practices, both material and emotional. Starting from Finch's (1989) classification of care practices, we considered how proximity/distance and mobility mediate these: sharing accommodation which, by definition, requires immediate proximity, personal care and nursing, and child care and practical support - being instrumental forms of support where frequent and/or immediate care is required, as is co-presence. In contrast, remittances - the provision of economic support - can be provided at-a-distance, although the rituals of gift giving make it preferable to enact such transfers during return visits. The third practice, affirmations of identities and roots, is concerned with territorial attachment, homecoming, the search for one's roots and belonging. Those visits, important in the reaffirmation, and the reshaping of identities, are place-specific as homecoming involves looking for and visiting landscapes, landmarks and places - sometimes resulting in abrupt discord between image and experience. 
VFR mobilities can also involve practices designed to assert various forms of territorial rights, relating to taxation, voting, and a range of other citizenship entitlements, as well as place-bound or associated consumption practices. Trust and cost are often reasons why those practices become an objective of VFR visits, more often a secondary one. Despite anecdotal evidence and limited research (e.g. Lee et al., 2010), the subject remains underresearched in the context of to-and-from mobilities. The last practice discussed in the paper is leisure tourism - defined as a form of hybrid travel (King 1996) where leisure practices are mixed with other practices. We identify a number of issues surrounding hosting, the meanings associated with visitors' experiences, and the phenomenon of VFR in third places. In the latter, complex family relations drive reunions in places other than natal homes, while cheap and accessible travel facilitates this.

While this article has explored conceptually five mutually constitutive practices related to VFR mobilities, these are necessarily highly contingent and require empirical research to tease out the complexities of how they are articulated. A number of other themes surrounding VFR movement remain neglected and need to be explored in future research. In terms of social relationships, there are important and under-researched social divisions of labour amongst kin and friends. For example, friends, neighbours or colleagues of friends, can be seen as serving important functions here - they are often involved in various aspects of hosting and caring - both at the practical level, such as picking up from the airport and entertaining when hosts are at work, and in terms of providing emotional support. Secondly, the implications of technological developments, particularly accessible travel with low-cost airlines have been noted earlier. We may add that those trips, as well as other trips, by car and by coach, tell us about another type of relationship, temporal co-ethnic ties. The close proximity of migrants travelling home allows them to perform their collective national identity at the airports and on the plane; from expressions of tensions, hostility, envy and drunken behaviour, to clapping on safe landing (Burrell 2008; 2011). Observing, evaluating and judging one another is also part of collective homecoming. Another issue that has not yet been addressed is the nature of other relationships, potentially ephemeral, built online between co-nationals with the same goal: for example, 
to travel by car to the same neighbourhood. The exchanges on internet fora for migrants suggest that this type of travel to one's homeland is increasingly popular - especially in some contexts (e.g. ridesharing or 'Mitfahrgelegenheit' in German cultures). Finally, there is scope for a more consciously gendered approach to researching these to-and-from mobilities - not only in relation to caring practices - but also to the other four practices. There are clearly significant implications of VFR-related care - requiring empirical research to deconstruct the complexities of a highly diverse set of flows.

The traditional model of longer term migration, or migration and return, has shifted towards more short-term or circular movements. Global relocations of highly skilled expats, movement of migrant workers, seasonal migrants, 'commuters', 'lifestyle migrants', international students flows as well as diasporic communities are some of the 'new' types of migration that are generating VFR flows. The increasing number of people leading differently constituted mobile lives, and the spatial dispersion of families across multiple geographical locations, raise questions of how they maintain, and reconstruct, their family life and friendships. In an age of the intensification, extensification, and changing composition of international migration, it is important to recognize that there are significant changes in VFR practices, and how these are often blurred and overlapping. 


\section{REFERENCES}

Ackers L, Dwyer P. 2004. Fixed laws, fluid lives: The citizenship status of post-retirement migrants in the European Union. Ageing and Society 24 : 451-475.

Annis DB. 1987. The meaning, value and duties of friendship. American Philosophical Quarterly 24 : 349-356.

Backer E. 2012. VFR travel: It is underestimated. Tourism Management 33 : 74-79.

Bailey AJ. 2001. Turning transnational: Notes on the theorisation of international migration. International Journal of Population Geography 7: 413-428.

Baldock CV. 2000. Migrants and their parents: caregiving from a distance. Journal of Family Issues, 21: 205-224

Basu P. 2004. My Own Island Home The Orkney Homecoming. Journal of Material Culture 9 27-42.

Basu P. 2007. Highland Homecomings: Genealogy and Heritage-Tourism in the Scottish Diaspora, London: Routledge.

Baxter LA, Bullis C. 1986. Turning points in developing romantic relationships. Human Communication Research 12: 469-493.

Baxter LA, Erbert L. 1999. Perceptions of dialectical contradictions in turning points of development in heterosexual romantic relationships. Journal of Social and Personal Relationships 16 : 547-569.

Benson M, O'Reilly K. 2009a. Migration and the search for a better way of life: A critical exploration of lifestyle migration. The Sociological Review 57 : 608-625.

Benson M, O'Reilly 2009b. Lifestyle migration: Expectations, aspirations and experiences. Farnham, Ashgate.

Bergmark R, Barr D, Garcia R. 2010. Mexican immigrants in the US living far from the border may return to Mexico for Health Services. Journal of Immigrant and Minority Health 12: 610-614. 
Binnie J, Edensor T, Holloway J, Millington S, Young C. 2007. Mundane mobilities, banal travels. Social and Cultural Geography 8 165-174.

Bischoff EE, Koenig-Lewis N. 2007. VFR tourism: The importance of university students as hosts. International Journal of Tourism Research 9: 465-484.

Blieszner R, Adams RG. 1992. Adult friendship. Newbury Park, CA: Sage.

Böcker A. 2008. International retirement migration: The legal framework and its effects on migrants' choices and behavior. Paper presented at the International Workshop on "Economic and Social Impact of International Retirement Migration (IRM): Antalya, an Emerging Destination in Southern Europe”, Antalya, Turkey, 7th-8th April.

Briggle A. 2008. Real friends: how the Internet can foster friendship. Ethics and Information Technology, 10: 71-79

Burrell K. 2008. Materialising the Border: Spaces of Mobility and Material Culture in Migration from Post-Socialist Poland. Mobilities 3: 353-373.

Burrell K. 2011. Going steerage on Ryanair: cultures of migrant air travel between Poland and the UK. Journal of Transport Geography 19: 1023-1030.

Canary DJ, Stafford L. 1994. Maintaining relationships through strategic and routine interaction. In DJ. Canary L. Stafford (Eds.), Communication and relational maintenance 3-22. San Diego: Academic Press.

Christou A. King R. 2010. Imagining 'home': Diasporic landscapes of the Greek-German second generation, Geoforum 41: 638-646

Cicirelli VG. 1995. Sibling Relationships across the Lifespan. New York: Plenum.

Cohen E. Cohen S. 2012. Current sociological theories and issues in tourism. Annals of Tourism Research 39: 2177-2202.

Coles TE, Timothy DJ. 2004. Tourism, diasporas, and space. Psychology Press.

Conradson D, Latham A. 2005. Friendship, networks and transnationality in a world city: Antipodean transmigrants in London. Journal of Ethnic and Migration Studies 31: 287-305. 
Cresswell T. 2010. Towards a Politics of Mobility. Environment and Planning D; Society and Space 28: 17-31.

Darieva T. 2011. Rethinking homecoming: diasporic cosmopolitanism in post-Soviet Armenia. Ethnic and Racial Studies 34: 490-508.

De Jong Gierveld J, Fokkema T. 1998. Geographical differences in support networks of older adults. Tijdschrift voor Economische en Sociale Geografie 89: 328-336.

Dobruszkes F. 2009. New Europe, low cost air services. Journal of Transport Geography 17: 423-432.

Finch J. 1989. Family Change and Social Obligations. Cambridge: Polity Press.

Geddes A. 2003. Migration and the welfare state in Europe. The Political Quarterly 74: $150-162$.

Graham B, Shaw J. 2008. Low-cost airlines in Europe: Reconciling liberalization and sustainability. Geoforum 39: 1439-1451.

Hagestad GO, 2000. Adults' intergenerational relationships, Generations and Gender Programme: Exploring future research and data collection options, 125-143. New York / Geneva: United Nations.

Hiltunen, MJ. Pitkänen, K. Vepsäläinen, M. Hall, CM. 2013. Second home tourism in Finland - current trends and ecosocial impacts. In Second homes in Europe: lifestyle issues to policy issues, Roca Z. Nazaré Roca, M, Oliveira, J(eds.); Ashgate Publishing, Aldershot; 165-199.

Hoffman E. 1991. Lost in Translation: A Life in a New Language. London: Minerva.

Hoang L, Brenda SA. Yeoh 2012. Sustaining Families across Transnational Spaces: Vietnamese Migrant Parents and their Left-Behind Children. Asian Studies Review 36: 307325.

Hardimon MO. 1994. Role obligations. The Journal of Philosophy 91: 333-363. 
Hung K, Xiao H, Yang X. 2013. Why immigrants travel to their home places: Social capital and acculturation perspective. Tourism Management 36 : 304-313.

Iorio M. Corsale A. 2012. Diaspora and Tourism: Transylvanian Saxons Visiting the Homeland. Tourism Geographies, (ahead-of-print), 1-35.

Jackson RT. 1990. VFR tourism: Is it underestimated. Journal of Tourism Studies 1: 10-17. Jain S. 2013. For love and money: second-generation Indian-Americans 'return' to India. Ethnic and Racial Studies 36: 896-914.

Johnson AJ. 2001. Examining the maintenance of friendships: Are there differences between geographically close and long distance friends?, Communication Quarterly 49: 424-435.

Johnson AJ, Wittenberg E, Villagran MM, Mazur M, Villagran P. 2003. Relational progression as a dialectic: Examining turning points in communication among friends Communication Monographs, 70: 230-249.

Joseph AE, Hallman BC. 1998. Over the hill and far away: distance as a barrier to the provision of assistance to elderly relatives. Social Science and Medicine 46: 631-639.

Jourard SM. 1971. Self-disclosure: An experimental analysis of the transparent self. New York: Wiley.

Karanfil G. 2009. Pseudo-exiles and reluctant transnationals: disrupted nostalgia on Turkish satellite broadcasts. Media, Culture and Society 31: 887-899.

King B. 1994. What is ethnic tourism? An Australian perspective. Tourism Management 15:173-176.

King B. 1996. VFR: A Future Research Agenda. In Yarman, H. R. (ed.), VFR Tourism: Issues and Implications. Melbourne: Victoria University of Technology, 86-89.

King R. Castaldo A. Vullnetari J. 2011a. Gendered Relations and Filial Duties Along the Greek-Albanian Remittance Corridor, Economic Geography 87: 393-419 
King R, Christou A, Ahrens J. 2011b. 'Diverse Mobilities': Second-Generation GreekGermans Engage with the Homeland as Children and as Adults. Mobilities 6: 483-501.

King R, Christou A, Teerling J. 2011c. We took a bath with the chickens': memories of childhood visits to the homeland by second generation Greek and Greek Cypriot 'returnees. Global Networks 11: 1-23.

Komter A, Vollebergh W. 1997. Gift Giving and the Emotional Significance of Family and Friends. Journal of Marriage and Family 59: 747-757.

Larsen J, Urry J, Axhausen KW. 2007. Networks and tourism: Mobile social life. Annals of Tourism Research 34: 244-262.

Lee C, Dwyer J. Coward R. 1990. Residential location and proximity to children among impaired elderly parents. Rural Sociology 55: 579-589.

Lee JY, Kearns RA, Friesen W. 2010. Seeking affective health care: Korean immigrants' use of homeland medical services, Health and Place 16 : 108-15.

Levitt P. 2009. Roots and Routes: Understanding the Lives of the Second Generation Transnationally. Journal of Ethnic and Migration Studies 35: 1225-1242.

Liefbroer AC, Mulder CH. 2006. Family obligations. In Dykstra PA. Kalmijn M. Knijn TCM. Komter AE. 2006 Family solidarity in the Netherlands, Amsterdam: Dutch University Press, 123-145.

Lin G, Rogerson PA. 1995. Elderly parents and the geographic availability of their adult children. Reseasrch on Ageing 17: 303-331.

Litwak E. 1960. Geographic mobility and extended family cohesion. American Sociological Review 25: 385-394.

Litwak E, Szelenyi I. 1969. Primary Group Structures and Their Functions: Kin, Neighbors, and Friends. American Sociological Review 34: 465-481.

Mason J. 2004. Managing Kinship over Long Distances: The Significance of 'The Visit'. Social Policy \& Society 3: 421-429. 
McGhee D, Heath S, Trevena P. 2013. Competing obligations and the maintenance of physical co-presence - the impact of migration and structural constraints on post accession Polish families in the UK. Families, Relationships \& Society 2: 229-245.

Moscardo G, Pearce P, Morrison A, Green D. O'Leary, JT. 2000. Developing a Typology for Understanding Visiting Friends and Relatives Markets. Journal of Travel Research 38: 251-259.

Mulder CH, Kalmijn M. 2006. Geographical distances between family members. In Dykstra PA. Kalmijn M. Knijn TCM. Komter AE. 2006. Family solidarity in the Netherlands, Amsterdam: Dutch University Press, 43-62.

Octavia JR, Hoven E, Van den Mondt H. de 2007. Overcoming the distance between friends. In Proceedings of the $21^{\text {st }}$ British Computer Society HCI Group Conference vol. 2, University of Lancaster.

Osipovič, D. 2013. 'If I Get Ill, it's onto the Plane, and off to Poland.'Use of Health Care Services by Polish Migrants in London. Central and Eastern European Migration Review 2: $21-38$

Palovic Z. Kam S. Janta H. Cohen SA. Williams AM. 2014. Conference communication: Surrey think tank: Reconceptualising Visiting Friends and Relatives (VFR) Travel. Journal of Destination Marketing \& Management, 2: 266-268.

Parreñas RC 2001. Mothering from a Distance: Emotions, Gender, and Intergenerational Relations in Filipino Transnational Families. Feminist Studies 27: 361-390.

Petridou E. 2001. The taste of home. In: Miller D. (Ed.), Home Possessions. Berg, Oxford, 87-104.

Rheingold H. 2000. The virtual community: Homesteading on the eletronic frontier (2nd ed.). Cambridge, MA: MIT Press

Rogerson PA, Weng, RH, Lin G. 1993. The spatial separation of parents and their adult children. Annals of the Association of American Geographers 83: 656-671. 
Rose S, Serafica FC. 1986. Keeping and ending casual, close and best friendships. Journal of Social and Personal Relationships, 3: 275-288.

Rossi A, Rossi P. 1990. Of human bonding. Parent-child relationships across the life course. New York: Aldine deGruyter.

Ruting B. 2012. 'Like touching with your roots': migrants' children visiting the ancestral homeland. Australian Geographer 43: 17-33.

Ryan L, Sales R, Tilki M. Siara B. 2009. Family strategies and transnational migration: recent Polish migrants in London. Journal of Ethnic and Migration Studies 35: 61-77.

Sayer A. 1992. Method in Social Science: a Realist Approach. Routledge: London.

Seaton AV. Palmer C. 1997. Understanding VFR tourism behaviour: The first five years of the United Kingdom tourism survey. Tourism Management 18: 345-355.

Shani A.Uriely N. 2012. VFR tourism: The host experience. Annals of Tourism Research 39: 421-440.

Silverstein M, Litwak E. 1993. A task-specific typology of inter-generational family structure in later life. The Gerontologist 33: 258-264

Stoller EP, Forster LE, Duniho TS. 1992. Systems of parent care within sibling networks. Research on Aging 14: 28-49.

Uriely N, 2010. "Home" and" away" in VFR tourism. Annals of Tourism Research 37 854857.

Urry J. 2002. 'Mobility and proximity'. Sociology 36: 255-274.

Teerling J. 2011. The Development of New 'Third-Cultural Spaces of Belonging': BritishBorn Cypriot 'Return' Migrants in Cyprus. Journal of Ethnic and Migration Studies 37: 1079-1099.

Walsh K. 2009. Geographies of the heart in transnational spaces: love and the intimate lives of British migrants in Dubai. Mobilities 4: 427-445. 
Wellman B, Haase AQ, Witte J, Hampton K. 2001. Community Commitment Does the Internet Increase, Decrease, or Supplement Social Capital? : Social Networks, Participation, and Community commitment. American Behavioral Scientist 45: 436.

Wellman B, Hampton K. 2001. 'Long distance community in the network society: contact and support beyond Netville'. American Behavioral Scientist 45: 477-496.

Wessendorf S. 2007. 'Roots migrants': transnationalism and 'return' among secondgeneration Italians in Switzerland. Journal of Ethnic and Migration Studies 33: 1083-1102.

Wessendorf S. 2010. Local attachments and transnational everyday lives: second-generation Italians in Switzerland. Global Networks 10: 365-382.

Williams AM, Baláž V. 2009. Low cost carriers, economies of flows, and regional externalities, Regional Studies 43: 677 - 691.

Williams AM, Chaban N, Holland M. 2011. The circular international migration of New Zealanders: Enfolded mobilities and relational places. Mobilities 6: 125-147.

Williams AM, Hall, CM. 2000a. Tourism and migration: New relationships between production and consumption. Tourism Geographies 2(: 5-27.

Williams AM, Hall CM. 2000b. Guest editorial: Tourism and migration. Tourism Geographies 2: 2-4.

Williams AM, Hall CM. 2002. Tourism, migration, circulation and mobility. In CM. Hall and AM. Williams (eds) Tourism and Migration: New Relationships between Production and Consumption, Dordrecht: Kluwer.

Williams AM, King R, Warnes A, Patterson G. 2000. Tourism and international retirement migration: New forms of an old relationship in southern Europe, Tourism Geographies 2: $28-49$ 